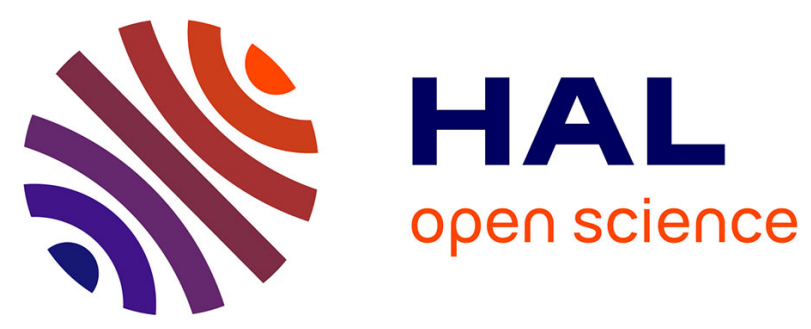

\title{
Complex dependence on the elastically active chains density of the strain induced crystallization of vulcanized natural rubbers, from low to high strain rate
} Nicolas Candau, Laurent Chazeau, J.-M. Chenal, Catherine Gauthier, Etienne Munch

\section{To cite this version:}

Nicolas Candau, Laurent Chazeau, J.-M. Chenal, Catherine Gauthier, Etienne Munch. Complex dependence on the elastically active chains density of the strain induced crystallization of vulcanized natural rubbers, from low to high strain rate. Polymer, 2016, 97, pp.158-166. 10.1016/j.polymer.2016.05.020 . hal-01804523

\section{HAL Id: hal-01804523 \\ https://hal.science/hal-01804523}

Submitted on 21 Jan 2022

HAL is a multi-disciplinary open access archive for the deposit and dissemination of scientific research documents, whether they are published or not. The documents may come from teaching and research institutions in France or abroad, or from public or private research centers.
L'archive ouverte pluridisciplinaire HAL, est destinée au dépôt et à la diffusion de documents scientifiques de niveau recherche, publiés ou non, émanant des établissements d'enseignement et de recherche français ou étrangers, des laboratoires publics ou privés.

\section{(c)(1) $\$$}

Distributed under a Creative Commons Attribution - NonCommerciall 4.0 International 


\title{
Complex dependence on the elastically active chains density of the strain induced crystallization of vulcanized natural rubbers, from low to high strain rate
}

\author{
Nicolas Candau ${ }^{\text {a, b }}$, Laurent Chazeau ${ }^{\text {a, b, *, Jean-Marc Chenal }}{ }^{\text {a, b }}$, Catherine Gauthier ${ }^{\text {, }}$ \\ Etienne Munch ${ }^{c}$ \\ ${ }^{a}$ Université de Lyon, CNRS, France \\ b MATEIS, INSA-Lyon, CNRS UMR5510, F-69621, France \\ ${ }^{c}$ Manufacture Française des Pneumatiques Michelin, Centre de technologies, 63040, Clermont Ferrand Cedex 9, France
}

\begin{abstract}
Strain Induced Crystallization (SIC) of Natural Rubbers (NR) with different network chain densities $(\nu)$ is studied. For the weakly vulcanized rubber, the melting stretching ratio $\lambda_{\mathrm{m}}$ at room temperature is the lowest. This is correlated with larger crystallites in this material measured by in situ WAXS, suggesting their higher thermal stability. SIC kinetics is then studied via stretching at various strain rates (from $5.6 \times 10^{-5} \mathrm{~s}^{-1}$ up to $2.8 \times 10^{1} \mathrm{~s}^{-1}$ ). For the slowest strain rates, SIC onset $\left(\lambda_{c}\right)$ is clearly the lowest in weakly vulcanized rubber. By increasing the strain rate, $\lambda_{c}$ of the different materials increase and converge. For the highest strain rates, $\lambda_{c}$ values still increase but less rapidly for the weakly vulcanized sample. This complex dependence on the elastically active chains (EAC) density of SIC has been confirmed by in situ WAXS during dynamic experiments and interpreted as a consequence of both the polymer chain network topology and of the entanglements dynamics.
\end{abstract}

\section{Introduction}

Sulphur vulcanized Natural Rubbers (NR) exhibit excellent mechanical properties which are closely related to their ability to crystallize under strain [1-5]. The thermal stability of the strain induced crystallites - characterized by their melting temperature is known to increase with the macroscopic stretching ratio, as shown by several experimental studies [6-9] as well as numerous theoretical works [10-12]. These theories also predict that the melting temperature should increase with the Elastically Active Chains density (so called hereafter EAC density, and labelled $\nu$ ); this last point is however not consistent with experimental results [7]. Such discrepancy is likely due to inappropriate hypotheses of these models, such as infinite crystallite sizes and homogeneous network. For instance, experimental works suggest that vulcanized rubber network is heterogeneous. Indeed, it is known that the complex reactions of several intermediate components used during

* Corresponding author. MATEIS, INSA de Lyon, Université de Lyon, CNRS, France. Tel.: +33(0)4 72438357 .

E-mail address: Laurent.chazeau@insa-lyon.fr (L. Chazeau). the curing step lead to the creation of heterogeneous $\mathrm{ZnO} / \mathrm{ZnS}$ clusters $[13,14]$. The influence of the heterogeneities in the network polymer chain on SIC was also suggested by in situ WAXS experiments which showed that only small portions of the chains strongly orient and crystallize during stretching while the others stay in the random coiled state [15]. Further experiments show that during stretching at relatively slow strain rates (from $10^{-3} \mathrm{~s}^{-1}$ to $\left.10^{-1} \mathrm{~s}^{-1}\right)$ and room temperature, SIC onset $\left(\lambda_{\mathrm{c}}\right)$ is around $4 / 4.5$, in spite of the different average density of elastically active chains $(\nu)$ in the tested materials [7,16,17]. Furthermore, Chenal et al. [16] found that the slope $\mathrm{dCI} / \mathrm{d} \lambda$ (where $\mathrm{CI}$ is the crystallinity index) first increases and then decreases as a function of the EAC density, highlighting an optimum for an intermediate value in the same range as the one of density of the chains between entanglement (equal to $1.5 \times 10^{-4} \mathrm{~mol} \mathrm{~cm}^{-3}$, as shown in ref. [18]). This result was later confirmed by the data from Tosaka et al. [19] which also showed a maximum of the $\mathrm{dCI} / \mathrm{d} \lambda$ slope for an intermediate EAC. According to Gonzalez et al. [20], the tensile strength is also optimum for this same EAC density. To sum up, the above results highlight the complex effect of chemical crosslinks, free and trapped entanglements on SIC, as well as the effect of the 
heterogeneous spatial distribution of the crosslinks. They suggest that the average network density is probably not the parameter to be only considered when SIC is studied.

It is worth noticing that the experimental approaches cited above do not inform on the kinetic behaviour of SIC, as their tests are most of the time performed at relatively slow strain rates. Only the recent works of Tosaka [21,22] propose a comparative study of SIC kinetics of natural rubbers with different average EAC densities $(v)$ ranging from $1.48 \times 10^{-4} \mathrm{~mol} \mathrm{~cm}^{-3}$ to $2.44 \times 10^{-4} \mathrm{~mol} \mathrm{~cm}^{-3}$, i.e. above the density of the physical entanglements. The coexistence of fast (from one to several decades of milliseconds) and slow (from one to several seconds) SIC processes were shown for all rubbers. Following the same author, SIC kinetics is faster for the rubber with the highest EAC density.

To complete the scarce data on SIC kinetic as a function of the average crosslink density, we propose a comparative study of SIC over a large strain rate domain, in rubbers with average EAC densities in the range $\left[0.99 \times 10^{-4} \mathrm{~mol} \mathrm{~cm}^{-3}\right.$ to $\left.1.76 \times 10^{-4} \mathrm{~mol} \mathrm{~cm}^{-3}\right]$. This selection is appropriate as it allows studying both undervulcanized and over-vulcanized (compared to the density of the physical entanglements). First, the melting process is analysed: a thermodynamic approach accounting for network heterogeneities and finite crystallite size is proposed. Crystallization is then studied through various thermomechanical paths in the strain rates range $\left[5.6 \times 10^{-5} \mathrm{~s}^{-1}, 2.8 \times 10^{1} \mathrm{~s}^{-1}\right.$ ] and temperature range $\left[21^{\circ} \mathrm{C}, 120^{\circ} \mathrm{C}\right]$. Crystallization during in situ WAXS dynamic cycles is finally performed over the strain rate range $\left[7.2 \mathrm{~s}^{-1}\right.$ to $\left.1.44 \times 10^{2} \mathrm{~s}^{-1}\right] \mathrm{s}$ in order to examine the influence of viscoelastic effects at high strain rates.

\section{Materials and methods}

\subsection{Materials}

The materials are crosslinked unfilled NR, obtained by vulcanization of gum (Technically Specified Rubber TSR20 provided by Michelin Tire Company) according to the recipe given in Table 1. The ratio Sulphur/CBS is kept constant for all the systems in order to ensure a same average length of the sulphur bridges in the processed materials. The material has been processed following the Rauline patent [23]. First, the gum is introduced in an internal mixer and sheared for $2 \mathrm{~min}$ at $60^{\circ} \mathrm{C}$. Then, the vulcanization recipe is added and the mix is sheared for $5 \mathrm{~min}$. The material is afterward sheared in an open mill for five minutes at $60^{\circ} \mathrm{C}$. Sample sheets are then obtained by hot pressing at $170{ }^{\circ} \mathrm{C}$ during $13 \mathrm{~min}$. Dumbbellshaped samples, with a $6 \mathrm{~mm}$ gauge length $\left(l_{0}\right)$ and $0.8 \mathrm{~mm}$ thickness, are machined. The average density of the elastically active chain $\nu$ is estimated from the swelling ratio in toluene and the Flory - Rehner equation [24] (Note that these values are very close to the ones deduced from the Mooney plot treatment of

Table 1

Samples recipes and network chain density estimated from swelling measurements.

\begin{tabular}{lccc}
\hline Sample code & $\mathrm{NR}_{0.8}$ & $\mathrm{NR}_{1,2}$ & $\mathrm{NR}_{1,6}$ \\
\hline Rubber & 100 & 100 & 100 \\
6PPD, phr & 3 & 3 & 3 \\
Stearic acid, phr & 2 & 2 & 2 \\
ZnO, phr & 1.5 & 1.5 & 1.5 \\
$\mathrm{CBS}^{\mathrm{a}}, \mathrm{phr}$ & 1.27 & 1.9 & 2.52 \\
Sulphur, phr & 0.8 & 1.2 & 1.6 \\
$\nu^{\mathrm{b}}$ & 0.99 & 1.42 & 1.76 \\
Sol. fraction (\%) & 4.0 & 4.0 & 2.6 \\
\hline
\end{tabular}

a $\mathrm{N}$-Cyclohexyl-2-benzothiazole sulfenamide.

b Average density of elastically active chains estimated from swelling measurement (in $10^{-4} \mathrm{~mol} \mathrm{~cm}^{-3}$ ). tensile tests). In order to avoid microstructure modification during the different mechanical tests, i.e. an uncontrolled Mullins effect, the samples are successively stretched, with the strain rate $1.1 \times 10^{-1} \mathrm{~s}^{-1}$, four times up to stretching ratio $(\lambda=7)$ higher than the maximum stretching ratio reached during the in situ cyclic tests $(\lambda=6)$.

\subsection{Mechanical and thermal characterization}

The EPLEXOR ${ }^{\circledR} 500 \mathrm{~N}$ of Gabo Qualimeter society (Ahlden, Germany) is used in order to carry out mechanical characterization at room temperature. Mechanical tests consist of a monotonic stretching at various strain rates (from $5.6 \times 10^{-5} \mathrm{~s}^{-1}$ to $1.1 \times 10^{-1} \mathrm{~s}^{-1}$ ), from the relaxed state up to the maximum stretching ratio $\lambda=6$. The test carried out at the lowest strain rate is stopped at an early stage ( $\lambda$ around 5 ) because the time of the experiment reaches the limitations of the experimental set up. The tensile force is converted into nominal stress $\sigma=F / S_{0}$. Stress is then plotted as a function of the stretching ratio $\lambda=1 / 1_{0}$. $\lambda$ is accurately measured by videoextensometry.

When vulcanized NR crystallizes under strain, its stress straincurves exhibit a relaxation followed by a stress-hardening. This is better visualized by plotting the tangent modulus $\mathrm{E}_{\mathrm{t}}$, defined as the derivative $d \sigma / d \lambda$, as a function of $\lambda$. It has been widely shown in literature that the stretching ratio at the beginning of this mechanical relaxation gives a good estimate of the crystallization onset $\lambda_{c}[7,8]$. Therefore $\lambda_{c}$ will be estimated as the stretching ratio at which $\mathrm{dEt} / \mathrm{d} \lambda$ is equal to zero.

For the highest strain rates tested. $\left(1.1 \times 10^{-1} \mathrm{~s}^{-1}\right.$ to $\left.2.8 \times 10^{1} \mathrm{~s}^{-1}\right)$, thermal characterization is carried out thanks to a tensile test machine (MTS). The temperature increase on the samples surface is measured thanks to an infrared pyrometer (Microepsilon, CTLF-CF3-C3) whose acquisition time is equal to $9 \mathrm{msec}$. Crystallization is an exothermic phenomenon and consequently has a thermal signature. Mitchell was the first to study SIC from the temperature variations of the sample surface [25]. A similar approach is used in the present study. Note that the thermal signature of strain induced crystallization has been elsewhere studied in recent works [26-28].

\subsection{In situ WAXS at slow strain rates}

The in situ WAXS experiments are carried out on the D2AM beamline of the European Synchrotron Radiation Facility (ESRF). The X-ray wavelength is $1.54 \AA$. Tests are performed in a temperature-controlled chamber. The following tests are performed: (i) cyclic loading at a constant strain rate and room temperature $\left(4.2 \times 10^{-3} \mathrm{~s}^{-1}\right)$, (ii) loading up to a maximum strain, relaxation and heating in the deformed state.

The two-dimensional (2D) WAXS patterns are recorded by a CCD camera (Princeton Instrument). The background, (i.e. air scattering and direct beam intensities) is properly measured in absence of any sample. It can then be subtracted to the total intensity scattered in the presence of the rubber sample. The corrected scattering intensity is finally normalized by the thickness and the absorption of the sample. Each scattering pattern is integrated azimuthally. The deconvolution of the curve $I=f(2 \theta)$ enables the extraction of the intensity at the peak top and the width at half height of each crystalline peak and the intensity at the peak top of the amorphous phase. The crystallinity index $\mathrm{Cl}$ is then determined as follows [29]:

$C I=\frac{I_{a 0}-I_{a \lambda}}{I_{a 0}}$

where $I_{a 0}$ and $I_{a \lambda}$ are the intensity of the amorphous phase at the 
peak top in the unstretched state and the stretched state, respectively. The average crystallite sizes $L_{\mathrm{hkl}}\left(L_{200}, L_{102}\right.$ and $\left.L_{002}\right)$ in the direction normal to the $(h k l)$ planes, are estimated from the Scherrer equation:

$L_{h k l}=\frac{K \lambda_{w}}{\beta_{1 / 2} \cos \theta}$

where $\lambda_{\mathrm{w}}$ is the wavelength and $\theta$ is the Bragg angle. In this study, each crystalline peak is fitted with a Lorentzian function in which the width at half-height is $\beta_{1 / 2}$. According to the parameters chosen for the fit of the experimental peak, the $\mathrm{K}$ value is 0.64 [30]. In order to measure the average crystallite size in the stretching direction $L_{002}\left(c_{1}\right)$, the tensile test machine is tilted by an angle around $10^{\circ}$. $L_{002}$ is found independent on the mechanical loading [31]. It is found equal to $75 \AA, 85 \AA$ and $94 \AA$ for $\mathrm{NR}_{1.6}, \mathrm{NR}_{1.2}$ and $\mathrm{NR}_{0.8}$ respectively. In reference 31 , an empiric relationship between the crystallites lateral sizes has been established: $b_{1} \sim a_{1} / 3$ with $L_{200}=a_{1}$ and $L_{020}=b_{1}$. It must be noted that such relationship has already been found in many other studies [7,16,17]. The $b_{1}$ value is deduced from the measurement of $L_{120}$. The angle between the plans (120) and (020) being equal to $19^{\circ}, b_{1}\left(L_{020}\right)$ is equal to $0.94 L_{120}$. Given the assumption of a parallepedic shape for the crystallites, the average volume of the crystallites is then defined by $\mathrm{V}=0.94 L_{120} L_{200} L_{002}$ and is therefore proportional to $L_{200}$ [2].

\subsection{In situ WAXS in dynamic conditions}

The in situ WAXS dynamic experiments are carried out on the Diffabs beamline of the French Synchrotron SOLEIL (Gif-Sur-Yvette). A specifically dedicated apparatus was developed in order to perform WAXS measurements during cyclic tensile tests with large amplitude and high frequencies (up to $40 \mathrm{~Hz}$ ) [32,33]. Thanks to a stroboscopic acquisition, the diffraction pattern is not averaged over the whole cycle, but is acquired at a chosen stretching ratio. In addition, the temperature increase of the material, which can be significant at high frequencies and large amplitude, is also estimated during the test thanks to the measurement of the sample surface temperature with an Infra-Red pyrometer (CTLF-CF3-C3 of Microepsilon, Saint Germain en Laye, France). The stroboscopic acquisition of the WAXS pattern at the chosen stretching ratio is made so that the exposure time is $1 / 44$ th of the time for a complete cycle. This means that a $1 \mathrm{~s}$ exposure time at given elongation needs an acquisition over 44 cycles. The device enables to dynamically stretch the samples over a fixed amplitude $\Delta \lambda$ ranging from 0 to several hundreds percent, around an average pre-stretch $\lambda_{\mathrm{a}}$ fixed at the beginning of the experiment. The testing procedure is the following: first, the sample is stretched (in $1 \mathrm{~s}$ ) at a fixed pre-stretch $\lambda_{\mathrm{a}}$, then, after $5 \mathrm{~min}$, dynamic deformation of amplitude $\Delta \lambda$ is started at a given frequency. Acquisition at $\lambda_{\min }, \lambda_{\max }$ and six intermediate stretching ratios is then performed after one minute, during $220 \mathrm{~s}$

\section{Results and discussion}

\subsection{Effect of $\nu$ on the thermal stability of crystallites}

Vulcanized rubbers are stretched and unstretched at $4.2 \times 10^{-3} \mathrm{~s}^{-1}$ strain rate and room temperature, from the undeformed state up to $\lambda=6$. As shown in Fig. 1, the stretching ratio at crystallization onset $\lambda_{c}$ is around 4.3 for all samples, which is consistent with the literature $[7,16,17]$. CI then increases and decreases during the loading and unloading steps respectively. The hysteretic shape of the curve is explained by the kinetics nature of the crystallization process while melting is characteristic of the equilibrium state. The melting stretching ratio $\lambda_{\mathrm{m}}$ increases from 2.5 to 3.3 when the average density $\nu$ increases, which is consistent with the results of Trabelsi et al. [7] $\mathrm{L}_{200}$ is plotted as a function of $\mathrm{CI}$ in Fig. 1b. Only data measured during the unloading phase are reported, but similar trend is observed during the loading phase. $\mathrm{L}_{2} 00$ - and thus the average volume $\mathrm{V}$ of the crystallites (cf. comments of section 2.3) - increases with CI. One must note that the increase of crystallite size with stretching ratio, and thus with $\mathrm{CI}$, is not systematically observed in the literature, e.g. references 7 or 17, which might be explained by the different methodologies of WAXS analysis used by the other authors. Our methodology was detailed and discussed in a previous paper [31]. For a given $\mathrm{CI}$, the crystallites size is always higher in the most weakly vulcanized sample. This larger crystallites size is associated with a lower melting stretching ratio $\lambda_{\mathrm{m}}$, in other word a higher thermal stability.

Melting is now studied at higher stretching ratio. Samples are stretched at room temperature and slow strain rate $\left(4.2 \times 10^{-3} \mathrm{~s}^{-1}\right)$ up to $\lambda=6$. They are then relaxed during five minutes in order to ensure a stabilization of the SIC process. Only weak variation of the crystalline structure is observed during this phase whatever the material. The samples are finally heated from room temperature up to the temperature of total melting of crystallites $\mathrm{T}_{\mathrm{m}}$. Figs. 2 and 3 present $\mathrm{CI}$ and $\mathrm{L}_{200}$ as a function of the time during the stretching and relaxation steps, and as a function of the temperature during the heating step. Melting of crystallites in stretched sample (at $\lambda=6$ ) is associated with a decrease of $L_{200}$, which is similar to the one observed during unloading at room temperature (Fig. 1). In particular, the sizes of the last crystallites that melt during heating at $\lambda=6$ or during unloading at room temperature are roughly the same. The melting curves $\mathrm{CI}(\mathrm{T})$ seem to converge and the temperature of total melting of crystallites is around $110{ }^{\circ} \mathrm{C}$ for $\mathrm{NR}_{1.6}$ and $\mathrm{NR}_{1.2}$ and $120{ }^{\circ} \mathrm{C}$ for $\mathrm{NR}_{0.8}$.

Classical SIC theories [10-12] predict that the melting temperature should increase when polymer chains are oriented by a macroscopic stretching of the sample. Numerous experimental works [6-9], as well as the present work, also show such a trend. According to the same theories, for a given stretching ratio, the melting temperature should be larger in highly vulcanized rubbers since the orientation of the chains should be stronger with smaller initial length between crosslinks. This is however not consistent with our experimental results which, like Trabelsi et al. [7], highlight a higher melting temperature of the stretched samples for the less vulcanized rubbers. This discrepancy is likely due to strong assumptions of these models, which assume infinite size of crystallites and also consider a homogeneous network chain density.

To account for the non-infinite size of the crystallites, Trabelsi [7] used a Gibbs-Thomson's type equation with a $\mathrm{T}_{\mathrm{m}, \infty}$ experimentally estimated for stretched sample. In a previous study [31], we used a slightly different approach: a single thermodynamic description, which contains the contribution of (i) the surface energy of the crystallites, (ii) the strain energy and (iii) the amorphous-crystalline phase transition energy, was proposed. Within the frame of this description, and from the experimental evolution of the average number of crystallites during SIC, it was proposed that crystallization was the result of successive appearance of crystallites of increasing size. The crystallites are assumed to grow spontaneously - compared to the time scale of the experiment - up to their maximum size (or saturation size) in all the directions orthogonal to the stretching direction $\left(a_{\mathrm{sat}}=\mathrm{a}_{1}\right.$ and $\left.b_{\text {sat }}=b_{1} \sim a_{1} / 3\right)$. The saturation size $c_{\text {sat }}$ along the stretching axis is a constant equal to $c_{1}$. Conversely, melting is the result of successive disappearance of these crystallite populations in the reverse order. Thus, it can be assumed that the crystallites size measured at $\lambda$ close to $\lambda_{\mathrm{m}}$ corresponds to that of the most stable crystallites. These crystallites are also the first to nucleate during loading. Then, 

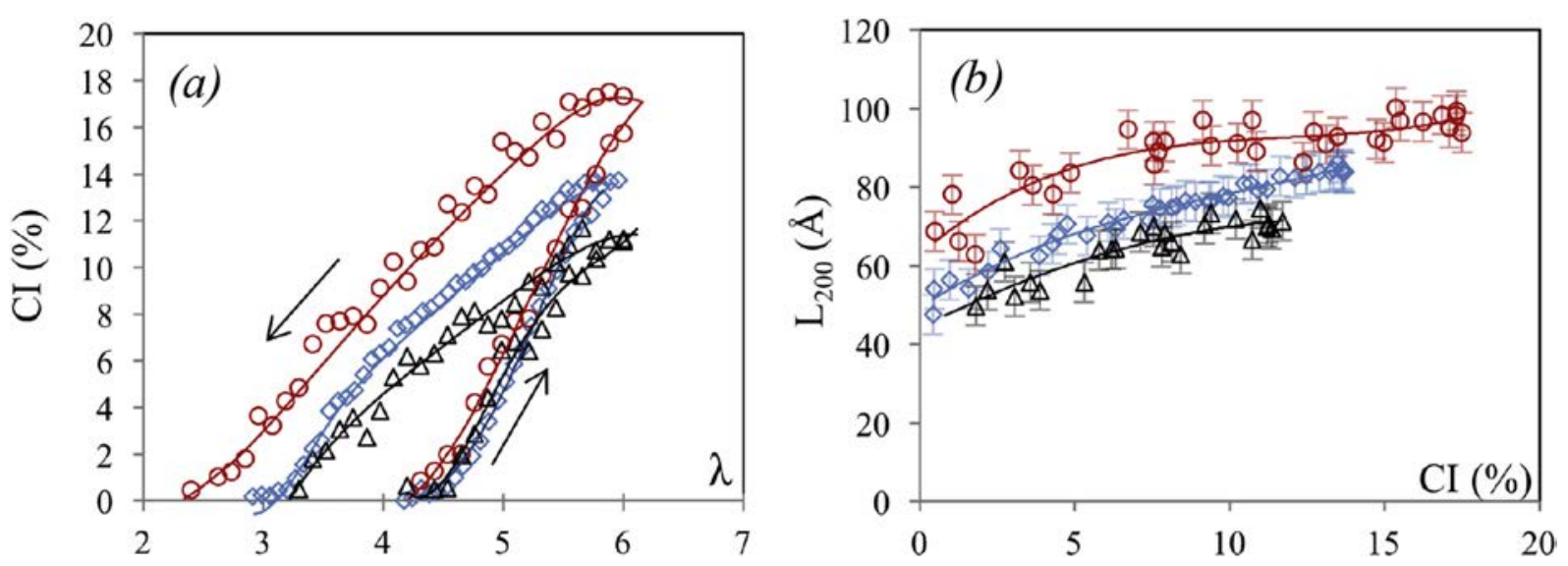

Fig. 1. (a) Cl during cyclic tests at room temperature with a $4.2 \times 10^{-3} \mathrm{~s}^{-1}$ strain rate for $\mathrm{NR}_{0.8}$ (circle symbols), $\mathrm{NR}_{1.2}$ (diamond symbols) and $\mathrm{NR}_{1.6}$ (triangle symbols). (b) $\mathrm{L}_{200}$ versus CI during the unloading phase of cyclic test. Lines are guides for the eyes.
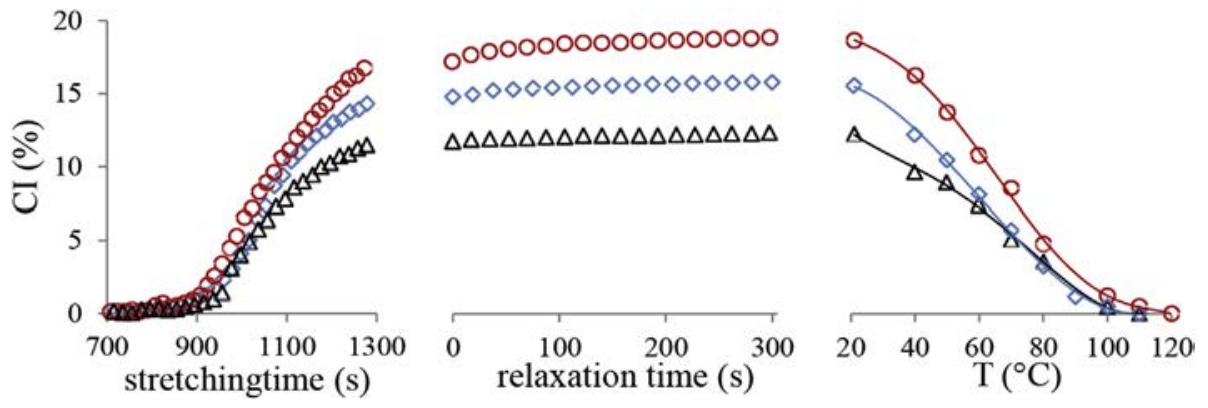

Fig. 2. Cl during stretching, relaxation and melting in the deformed state $\lambda=6$ for $\mathrm{NRS}_{0.8}$ (circle symbols), $\mathrm{NRS}_{1.2}$ (diamond symbols) and $\mathrm{NRS} \mathrm{S}_{1.6}$ (triangle symbols) samples.
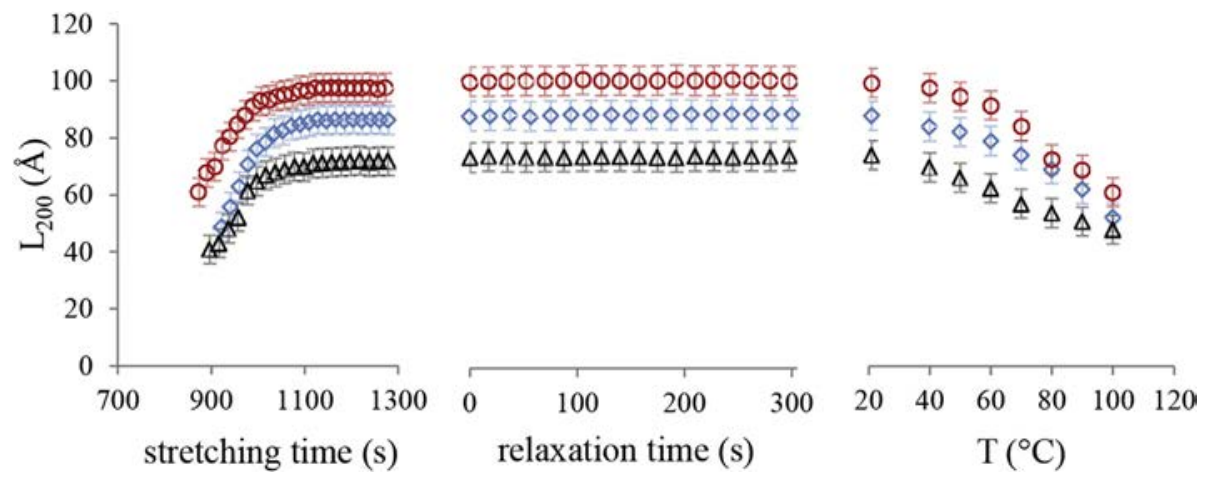

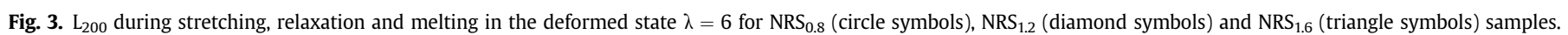

assuming an affine deformation of chains, as proposed by Krigbaum et al. [11], it has been proposed in a previous paper [34] an estimate of the melting temperature $\mathrm{T}_{\mathrm{m}}$ as a function of the melting stretching ratio $\lambda_{\mathrm{m}}$ and crystallites size:

$T_{m}=\frac{T_{m, \infty}\left(1-\frac{1}{\Delta H_{m}}\left(\frac{8 \sigma_{l}}{a_{\text {sat }}}+\frac{2 \sigma_{e}}{c_{\text {sat }}}\right)\right)}{1-\frac{\nu_{1} R T_{m, \infty}}{2 \Delta H_{m}}\left(\lambda_{m}^{2}+\frac{2}{\lambda_{m}}-3\right)}$

where the melting enthalpy $\Delta \mathrm{H}_{\mathrm{m}}$ is equal to $6,1 \times 10^{7} \mathrm{~J} \mathrm{~m}^{-3}$ whatever the network chain density considered [35], the melting temperature of the infinite crystal in the undeformed state $\mathrm{T}_{\mathrm{m}, \infty}$ is equal to $35.5{ }^{\circ} \mathrm{C}$ [36], $\mathrm{R}$ the constant of the perfect gazes
$\left(\mathrm{R}=8.314 \mathrm{~J} \mathrm{~mol}^{-1} \mathrm{~K}^{-1}\right)$, and $\lambda_{\mathrm{m}}$ the melting stretching ratio. $\mathrm{c}_{\mathrm{sat}}$ $\left(\mathrm{L}_{002}\right)$ is experimentally measured (see section 2.3$)$; $\mathrm{a}_{\mathrm{sat}}\left(\mathrm{L}_{200}\right)$ corresponding to the incipient crystalline structure ( $\mathrm{CI} \sim 0.5 \%$ ) is found equal to $44 \AA$, $50 \AA$ and $68 \AA$ for $\mathrm{NR}_{1.6}, \mathrm{NR}_{1.2}$ and $\mathrm{NR}_{0.8}$ respectively (Fig. 1b). Assuming heterogeneities of the network, $v_{1}$ is not the average value of the macroscopic average density of the elastically active chains (EAC), but the local density of the EAC forming the most stable crystallites. Surface energies are assumed to depend solely on $\Delta \mathrm{H}_{\mathrm{m}}$ as proposed by Hoffman [37]. Their values were estimated in a previous work [31] $\left(\sigma_{\mathrm{e}}=0.66 \times 10^{-2} \mathrm{Jm}^{-2}\right.$ and $\sigma_{1}=0.33 \times 10^{-2} \mathrm{Jm}^{-2}$ ). Recently, Gros et al. [38] gave an estimate of $\sigma_{1}^{2} \sigma_{e}$ for the crystallite nuclei, which they think mainly of bundle type. Our estimate of $\sigma_{1}^{2} \sigma_{\mathrm{e}}$ used here to discuss the crystallites melting temperature is 10 times larger. Such value, justified from 
literature enabled to deduce a reasonable estimate of the local EAC density from our experimental data (taking values of Gros et al. in our model would have given an unrealistic value of $25.10^{-4} \mathrm{~mol} \mathrm{~cm}^{-3}$ in experiment presented in reference 31), and a good prediction of the temperature at total melting of stretched samples [34]. Following the arguments of Gros et al., our estimate of $\sigma^{2} \sigma_{e}$ is consistent with the idea of crystallites made from oriented chains nuclei and then grown with folded chains.

From the knowledge of the size of the most stable crystallites, equation (3) - taken with $\mathrm{T}_{\mathrm{m}}$ equal to room temperature - gives access to $\nu_{1}$, whose value is found equal to $4.03,4.11$ and $4.14 \times 10^{-4} \mathrm{~mol} \mathrm{~cm}{ }^{-3}$ for $\mathrm{NR}_{0.8}, \mathrm{NR}_{1.2}$, and $\mathrm{NR}_{1.6}$ respectively. This suggests that, for the studied systems, the increase of the crosslinks number does not lead to the creation of crystallisable domains with an EAC density higher than $\nu_{1}$. Domains with larger EAC density $\left(\nu>\nu_{1}\right)$ potentially exist (cf. thermoporosimetry experiments in Fig. 10 of the appendix) and their volume fraction might increase with vulcanization. However, these domains are inefficient in terms of SIC, as they are maybe too dense to allow chains organization as crystallites. On the contrary, the presence of these domains in the vicinity of the crystallites might stop their growth.

From the knowledge of all parameters in equation (3), the relation between $T_{m}$ and $\lambda_{m}$ can be estimated for temperatures above room temperature (Fig. 4). The values of $\lambda_{m}$ and $T_{m}$ extracted from the above experiments are also plotted (cyclic deformation at room temperature and melting at $\lambda=6$ ). As previously said, at room temperature, the differences of $\lambda_{\mathrm{m}}$ are explained by the differences in the crystallites size. The data are very well described by equation (3).

\subsection{SIC kinetics of vulcanized natural rubbers}

As a first approach, SIC kinetics is studied through the analysis of the mechanical behaviour. NR samples are stretched from the undeformed state up to $\lambda=6$ at room temperature and various strain rates. Fig. 5 presents the evolution of the stress-strain curves for strain rates varying from $\mathrm{v}_{1}=5.6 \times 10^{-5} \mathrm{~s}^{-1}$ to $\mathrm{v}_{3}=1.1 \times 10^{-1} \mathrm{~s}^{-1}$. The tangent moduli $E_{t}$ are given in insert as a function of the stretching ratio. At sufficiently low stretching ratio (between $\lambda=1$ and $\lambda=3.5$ ), chains have not crystallized yet and stress-strain curves can be modelled by a hyperelastic constitutive equation. However, the weakly vulcanized rubber is significantly sensitive to strain rate, indicating a viscoelastic behaviour. At larger stretching ratio, the shortest chains (with the network density $\nu_{1}$ ), are

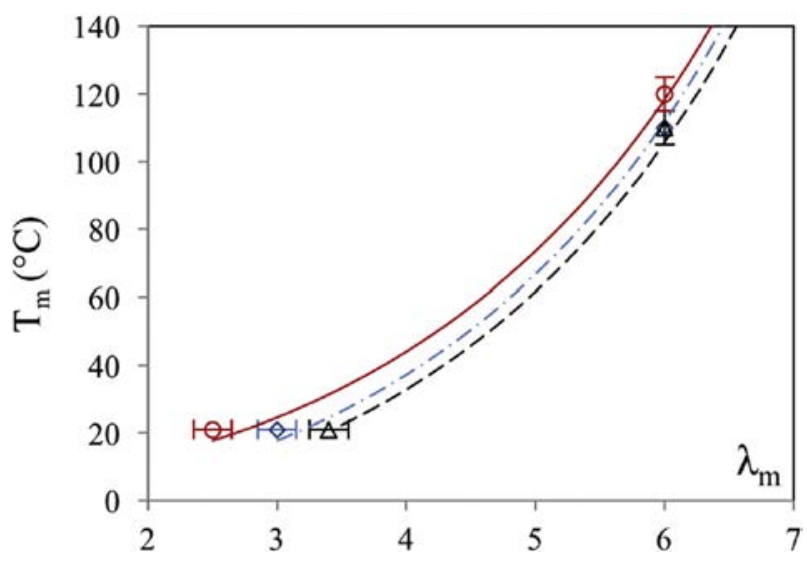

Fig. 4. Melting temperature of $\mathrm{NR}_{0.8}$ (circle symbols), $\mathrm{NR}_{1.2}$ (diamond symbols) and $\mathrm{NR}_{1.6}$ (triangle symbols) deduced from tensile loading and unloading $\left(v_{2}=4.2 \times 10^{-3} \mathrm{~s}^{-1}\right)$ at room temperature and melting under strain $(\lambda=6)$. Solid line, theoreticals curves deduced from Eq. 3. sufficiently oriented to crystallize. A stress relaxation, associated with SIC onset, clearly visible on the stress-strain curves, enables to estimate $\lambda_{c}$ for the strain rates $5.6 \times 10^{-5} \mathrm{~s}^{-1}, 4.2 \times 10^{-3} \mathrm{~s}^{-1}$ and $1.1 \times 10^{-1} \mathrm{~s}^{-1}$. It is recalled (see section 2.2) that the stretching ratio at the beginning of this mechanical relaxation gives a good estimate of the crystallization onset $\lambda_{c}[7,8]$. For larger strain rates, $\left(5.6 \mathrm{~s}^{-1}\right.$ and $2.8 \times 10^{1} \mathrm{~s}^{-1}$ ), the thermal response of $\mathrm{NR}_{0.8}$ and $\mathrm{NR}_{1.2}$ samples is used to estimate their $\lambda_{c}$ (refer to Fig. 11 in the appendix).

$\lambda_{c}$ values measured through mechanical and thermal responses are plotted as a function of the strain rate in Fig. $6 \lambda_{c}$ progressively increases in all samples when increasing the strain rate. This is mainly due to the time needed for the nucleation of the incipient crystallites to occur, as suggested in previous papers [2,12]. Despite the difference in the average crosslink density of $\mathrm{NR}_{1.2}$ and $\mathrm{NR}_{1.6}$, they both show a very similar dependence of $\lambda_{c}$ with the strain rate, in the tested range $\left[5.10^{-5} \mathrm{~s}^{-1} ; 2 \times 10^{-1} \mathrm{~s}^{-1}\right]$, indicating a same nucleation kinetic.

For intermediate strain rate (from $10^{-3}$ to $10^{-1} \mathrm{~s}^{-1}$ ), $\lambda_{\mathrm{c}}$ of $\mathrm{NR}_{0.8}$ is close to the one of the two other NR. In this strain rate range, the more viscoelastic behaviour of this sample does not have consequence on the apparent nucleation kinetic. These results thus confirm those in the literature usually reported within this range of strain rates, showing that $\lambda_{c}$ does not depend on the average EAC density $[7,16,17]$. It is however noteworthy that the number of crystallites formed during the stretching is significantly lower in $\mathrm{NR}_{0.8}$ as the total crystallinity is the same as the one of $\mathrm{NR}_{1.2}$ and the crystallites dimensions around 15\% larger.

When the strain rate increases, it is expected for all the samples an increase of $\lambda_{c}$ as crystallite nucleation needs time to occur. Interestingly, for the largest strain rate, (from $10^{-1}$ to $10^{1} \mathrm{~s}^{-1}$ ), $\lambda_{\mathrm{c}}$ of $\mathrm{NR}_{1.2}$ increases with the strain rate much more rapidly than $\lambda_{\mathrm{c}}$ of $\mathrm{NR}_{0.8}$. An explanation might be found in the weaker crosslink density of $\mathrm{NR}_{0.8}$ vulcanized rubber: the remaining free entanglements (evidenced by the viscoelastic behaviour of this sample) might act as supplementary permanent crosslinks when the strain rate is sufficiently high to avoid their disentanglement. This creates new potential nucleating domains for nucleation. As a result, the nucleation probability increases in the samples, counterbalancing the expected effect of the strain rate increase.

Unexpectedly, for the lowest strain rates (from $10^{-5}$ to $10^{-3} \mathrm{~s}^{-1}$ ), $\lambda_{c}$ is again found lower for the weakly vulcanized rubber. From a thermodynamic point of view, nucleation can occur at a lower stretching ratio if the experimental time is sufficiently increased to compensate the lower nucleation probability [31]. However, there is a limitation to this mechanism as a lower nucleation probability is related to a larger critical nucleus size (below which the crystallite is not stable). In other words, when the strain rate is decreased, the experimental time given to the sample to crystallize at a given stretching ratio is increased, and such time might be in the range of the time needed to nucleate larger critical nucleus. However, it is mandatory that the size of this nucleus stay compatible with the network topology of the elastomer. Within this frame, in $\mathrm{NR}_{0.8}$, we could assume that this is the case. Contrarily, in $\mathrm{NR}_{1.2}$, the limitation of the critical size of the nucleus by the network topology becomes effective when the strain rate is decreased: this limits the decrease of $\lambda_{c}$.

In industrial applications (e.g. pneumatic tires), rubber is generally submitted to complex solicitations, such as cyclic ones at high frequency. With the aim of applying more realistic mechanical conditions than a simple monotonic stretch, and also to directly observe SIC through in situ WAXS, cyclic tests are carried out thanks to the experimental device described in section 2.4. $\mathrm{NR}_{0.8}, \mathrm{NR}_{1.2}$ and $\mathrm{NR}_{1.6}$ samples are first quickly pre-stretched at $\lambda_{\mathrm{a}}=3.9$ and let relaxed in the deformed state during five minutes. Samples are then dynamically deformed around $\lambda_{\mathrm{a}}$ with an amplitude $\Delta \lambda=\lambda_{\max }$ 

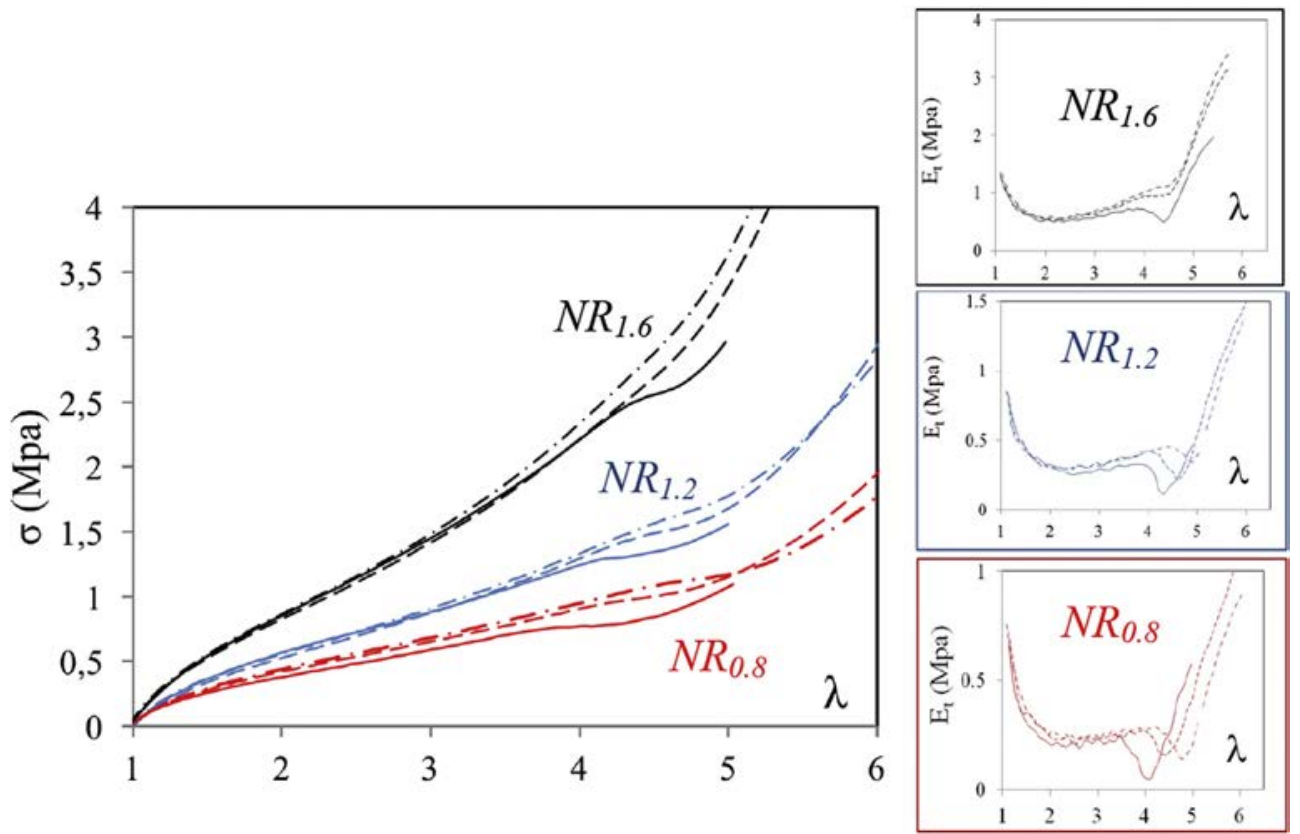

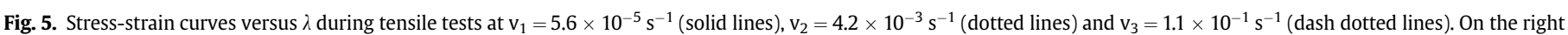
are plotted the tangent moduli $\mathrm{E}_{\mathrm{t}}$ versus $\lambda$.

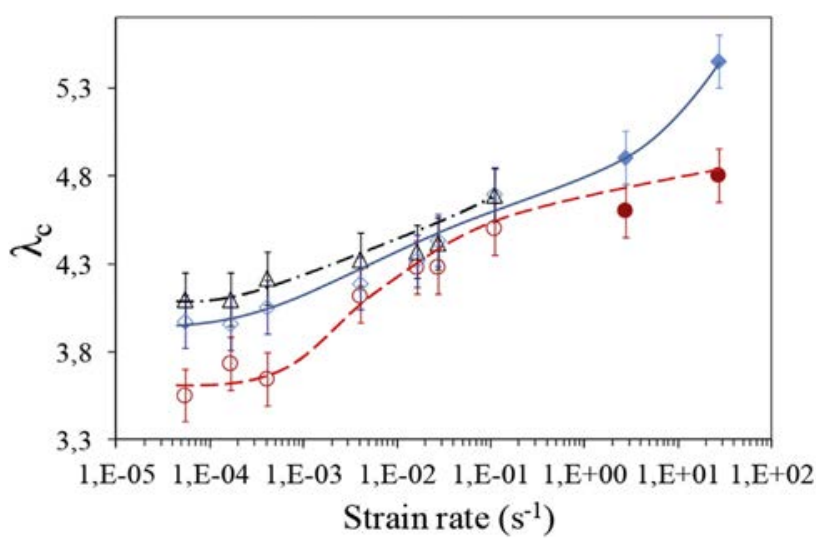

Fig. 6. $\lambda_{c}$ values extracted from mechanical (open symbols) and thermal (close symbols) tests as a function of the strain rate for $\mathrm{NR}_{0.8}$ (circle symbols, dotted line), $\mathrm{NR}_{1.2}$ (diamond symbols, solid line) and $\mathrm{NR}_{1.6}$ (triangle symbols, dashed dotted line) samples. Lines are guide for the eyes.

- $\lambda_{\min }=1.8$. The frequency varies from $2 \mathrm{~Hz}$ to $40 \mathrm{~Hz}$, and the corresponding strain rates extend from $7.2 \mathrm{~s}^{-1}$ to $144 \mathrm{~s}^{-1}$. The important point here is that for fixed pre-stretched and dynamic amplitude, the dynamic cycle evolves totally $\left(\mathrm{NR}_{0.8}\right.$ and $\left.\mathrm{NR}_{1.2}\right)$ or partially $\left(\mathrm{NR}_{1.6}\right)$ above the melting stretching ratio $\lambda_{\mathrm{m}}$ at room temperature (as schemed in Fig. 7), if one assumes that $\lambda_{\mathrm{m}}$ is independent of the strain rate of the cycle.

The evolution of the crystalline cycles during dynamic tests for $\mathrm{NR}_{1.2}$ and $\mathrm{NR}_{1.6}$ samples is presented in Fig. 8. Slow strain rate cycles are added for comparison. Because $\lambda_{\min }$ is below or close to $\lambda_{\mathrm{m}}$ (for $\mathrm{NR}_{1.6}$ and $\mathrm{NR}_{1.2}$ respectively) at room temperature (deduced from the unloading phase of the slow strain rate cycle at room temperature), $\mathrm{Cl}$ at $\lambda_{\min }$ is expected to be equal or close to zero, whatever the frequency tested, as found experimentally. For both materials, $\mathrm{Cl}$ increases from $\lambda_{\min }$ to $\lambda_{\max }$ and decreases from $\lambda_{\max }$ to $\lambda_{\min }$. Thus, some SIC is found for all the frequencies, for both $\mathrm{NR}_{1.2}$ and $\mathrm{NR}_{1.6}$. Looking back at the results presented in Fig. 6, at $2 \mathrm{~Hz}$, which

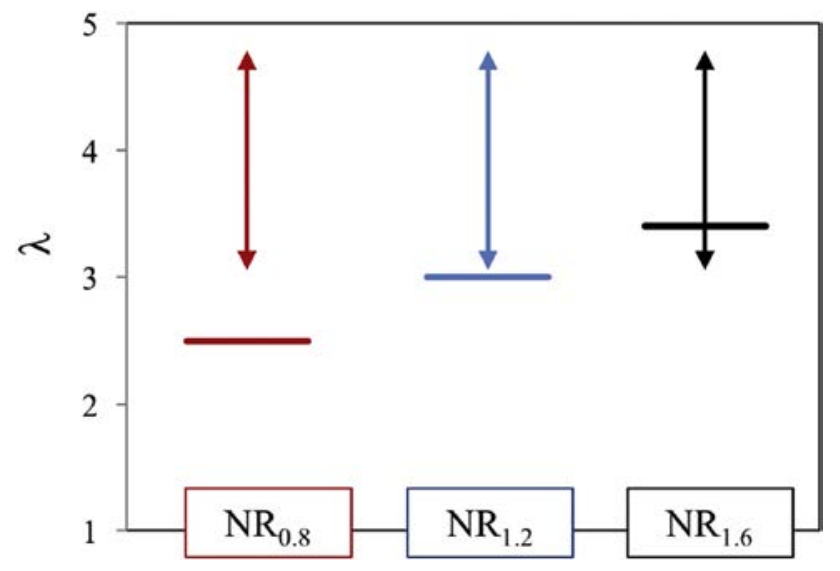

Fig. 7. $\lambda$ domain of the dynamic stretching ratio (vertical arrows) and $\lambda_{\mathrm{m}}$ at room temperature deduced from Fig. 1 (horizontal lines).

corresponds to a maximum strain rate of $7.2 \mathrm{~s}^{-1}$ (maximum as the strain cycle is a sinewave), $\lambda_{c}$ of $N_{1.2}$ becomes very close to $\lambda_{\max }$. Unfortunately, we did not perform measurements for $\mathrm{NR}_{1.6}$, but we can assume that this is also the case for $\mathrm{NR}_{1.6}$. This should lead to a very weak SIC whatever the tested frequencies. Nevertheless, the measured SIC stays significant at $2 \mathrm{~Hz}$ and above. This might be explained by viscoelastic effects at these large frequencies, as discussed further with $\mathrm{NR}_{0.8}$ for which these effects are much more obvious. Here, with $\mathrm{NR}_{1.2}$ and $\mathrm{NR}_{1.6}$, they do not need to be important, as a small reduction of $\lambda_{c}$ at $2 \mathrm{~Hz}$ (maybe due to some trapping of entanglement at high strain rate) is sufficient to explain the obtained results. Indeed, even if the onset of crystallization for the first loading phase is only slightly below $\lambda_{\max }$ at $2 \mathrm{~Hz}$, the protocol of our experiment explains that SIC can be also measured at $15 \mathrm{~Hz}$ : as found in a previous work [31], the chains of the crystallites which have molten during unloading seem to keep the memory of their previous alignment, this facilitates the crystallites re-nucleation during the following loading step and therefore leads 

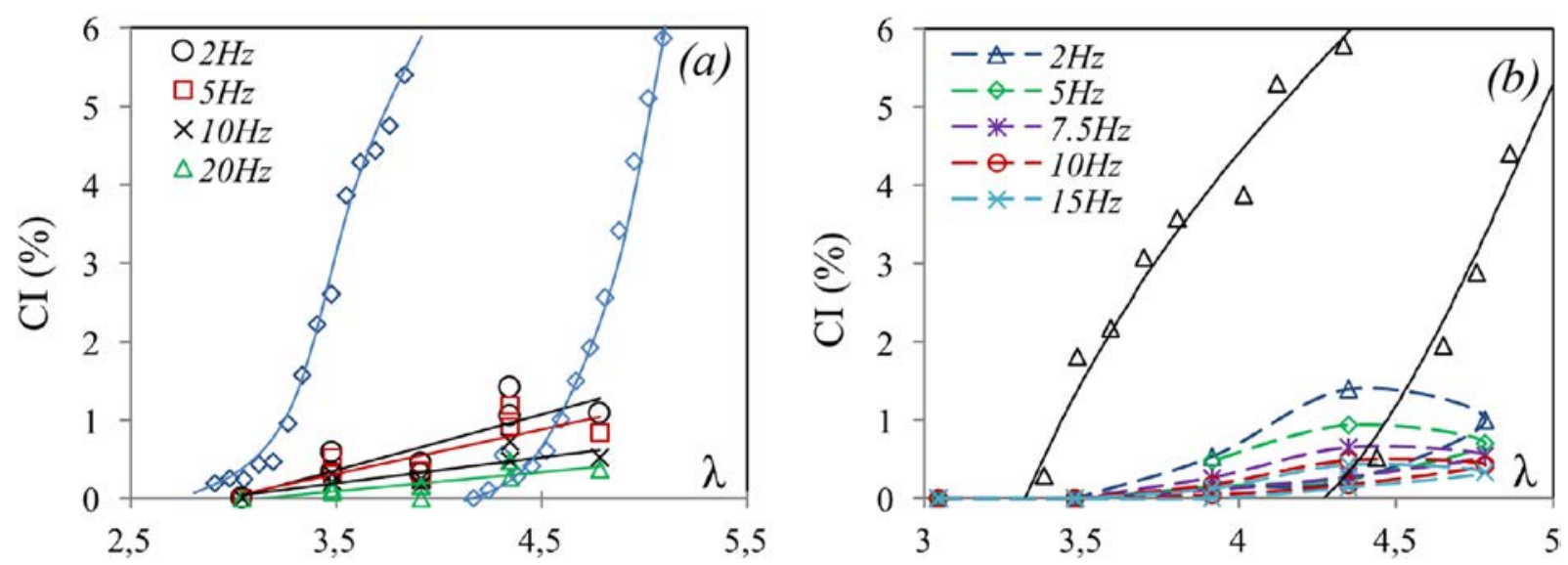

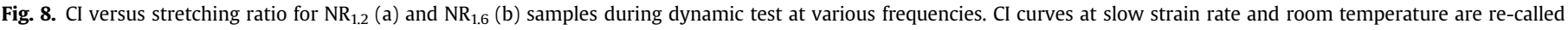
(same data of Fig. 1).

to a decrease of the onset of crystallization down to $\lambda_{\mathrm{m}}$. One observe however that SIC becomes weaker when the frequency increases above $2 \mathrm{~Hz}$, because of self-heating effect which has also to be taken into account: it is known to lead to an increase of the stretching ratio for both nucleation and melting of the different crystallite populations $[2,33]$.

Fig. 9 now displays the evolution of $\mathrm{CI}$ of $\mathrm{NR}_{0.8}$ during dynamic cycles. At $2 \mathrm{~Hz}$, a residual $\mathrm{CI}$ is measured at $\lambda_{\min }$. This is expected because (i) $\lambda_{\min }$ is above $\lambda_{\mathrm{m}}$ at room temperature and (ii) selfheating at this frequency is negligible. However, $\mathrm{CI}$ at $\lambda_{\min }$ becomes null between $10 \mathrm{~Hz}$ and $20 \mathrm{~Hz}$. For these frequencies, the surface temperature is found equal to 29 and $31{ }^{\circ} \mathrm{C}$ respectively, due to a self-heating (complete data can be found in reference 31 for the $\mathrm{NR}_{1.2}$ sample, and measurements carried out on the $\mathrm{NR}_{0.8}$ sample show very similar results). At these temperatures, $\lambda_{\mathrm{m}}$ estimated from equation (3) is found equal to 3.2 and 3.3 respectively, i.e. just above $\lambda_{\text {min }}$. Thus, assuming the equivalence between self-heating and heating brought by an external source, and also that $\lambda_{\mathrm{m}}$ is only temperature but not strain rate dependent, $\mathrm{CI}$ disappearance at $\lambda_{\min }$ for frequency above $10 \mathrm{~Hz}$ is well explained. Same reasoning applied to synthetic rubber [39] or filled NR [40] tested in same conditions led to similar conclusions.

Contrarily to the CI curve of $\mathrm{NR}_{1.2}$ and $\mathrm{NR}_{1.6}$, the $\mathrm{CI}$ curves of $\mathrm{NR}_{0.8}$ exhibit large hysteretic shape at $2 \mathrm{~Hz}$. The $\mathrm{CI}$ measured at the beginning of the unloading $(11.5 \%)$ is much higher than the

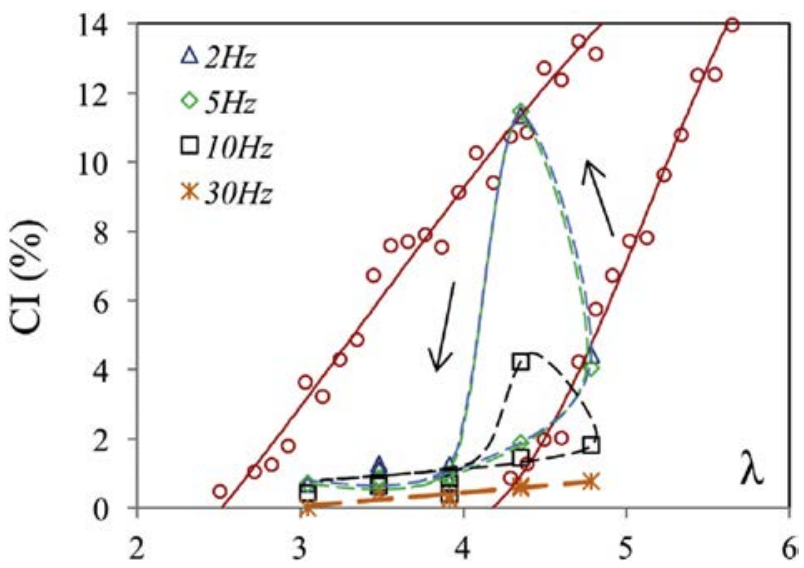

Fig. 9. $\mathrm{CI}$ versus stretching ratio for $\mathrm{NR}_{0.8}$ sample during dynamic test at various frequencies. CI curves at slow strain rate and room temperature are re-called (cf. Fig. 1). maximum value that would be expected if the cycle was carried out at slow strain rate: $4.5 \%$, which is the value measured at $\lambda=\lambda_{\max }$ during the loading phase of the cyclic test at slow strain rate. During unloading, $\mathrm{CI}$ then immediately decreases down to $1 \%$. This acceleration of melting compared to the unloading curve at slow strain rate might be due to the fact that the amorphous chains surrounding the crystallites do not have sufficient time to relax and to make the crystalline phase stable [33]. Note that an increase of the frequency from $2 \mathrm{~Hz}$ to $5 \mathrm{~Hz}$ does not change the cycle shape. These results confirm the larger ability of this material to crystallize at high strain rates, compared to more vulcanized sample. They are in agreement with the result of Fig. 6 . Indeed, in the same range of strain rates (from $1 \mathrm{~s}^{-1}$ to $10 \mathrm{~s}^{-1}$ ), it was found the lowest values of $\lambda_{\mathrm{c}}$ for $\mathrm{NR}_{0.8}$. At $2 \mathrm{~Hz}$, the size of the crystallites at the maximum of $\mathrm{CI}$ has been astonishingly found around $110 \AA$, i.e. much above the largest crystallite average size found at low strain rate (cf. Fig. 1b). Thus, at $2 \mathrm{~Hz}$, by comparison with slow strain rate cycle, the crystallinity might be the results of a larger amount of large crystallites. In addition, it is noteworthy that (i) the largest $\mathrm{CI}$ is not found at the maximum stretching ratio, but at a stretching ratio slightly lower, and (ii) the $\mathrm{CI}$ increase is very large between these two stretching ratios. This indicates complex viscoelastic effects probably related to the dynamics of the entanglements in the material, and which, for a part of them, are not trapped by the chemical crosslinks, as it is mainly the case in more crosslinked sample (for instance $\mathrm{NR}_{1.2}$ ). As previously said, we think that these entanglements might act, at large strain rate, as supplementary crosslinks enabling an easier nucleation of the crystallites, and might also have sufficient mobility (as they are not completely trapped by the chemical crosslinks) to enable the growth of larger crystallites from the nuclei.

As expected, at $10 \mathrm{~Hz}$ and above, self-heating and the nucleation time, which turns out to be too large compared to the experimental time, probably become the predominant effects. It should be recalled that this frequency corresponds to an experimental time which is in the range of the characteristic times for SIC recently measured by different authors [21,33,41,42]. For frequencies above $10 \mathrm{~Hz}, \mathrm{CI}$ decreases with the frequency, like it was also observed for the more vulcanized rubbers $\mathrm{NR}_{1.2}$ and $\mathrm{NR}_{1.6}$.

\section{Conclusion}

The effect of the average EAC density on Strain Induced Crystallization (SIC) and melting of vulcanized natural rubbers (NR) is investigated with $3 \mathrm{NR}$ with different EAC densities. The melting 
process is first analysed from WAXS experiments. At room temperature, the melting stretching ratio $\lambda_{\mathrm{m}}$ is found lower for the weakly vulcanized sample (higher thermal stability), which is assumed to be due to its larger crystallites size. Accounting for the fact that crosslink densities heterogeneities are present in the material, a thermodynamic description taking into account the crystallites size and the melting stretching ratio is then used to estimate the density of the first chains involved in SIC (assumed to be also the last to melt). This density $\left(\nu_{1}\right)$ is found similar for all the studied rubbers. Moreover, this description allows predicting the evolution of the melting temperature with the stretching ratio. A good agreement is found with experimental data.

SIC kinetics is then studied via stretching at various strain rates. Mechanical analysis is performed between $5.6 \times 10^{-5} \mathrm{~s}^{-1}$ and $1.1 \times 10^{-1} \mathrm{~s}^{-1}$ and thermal analysis between $5.6 \mathrm{~s}^{-1}$ and $2.8 \times 10^{1} \mathrm{~s}^{-1}$. For the slowest strain rates studied (from $5.6 \times 10^{-5} \mathrm{~s}^{-1}$ to $4.2 \times 10^{-4} \mathrm{~s}^{-1}$ ), SIC onset $\lambda_{\mathrm{c}}$ is clearly lower in the most weakly vulcanized rubbers. This might be explained by the ability of such material to form large crystallites nuclei. For strain rates increasing in the range $\left[4.2 \times 10^{-3} \mathrm{~s}^{-1}, 1.1 \times 10^{-1} \mathrm{~s}^{-1}\right]$, stretching ratios at the SIC onsets increase and converge for the three tested NR, as commonly found in various works from the literature using similar materials and strain rates. However, when strain rate increases in the range $1.1 \times 10^{-1} \mathrm{~s}^{-1}$ up to $2.8 \times 10^{1} \mathrm{~s}^{-1}$, $\lambda_{c}$ of the different rubber also increases but less rapidly for the weakly vulcanized sample. Such behaviour is likely related to the more numerous entanglements in this rubber. These ones have a complex effect on SIC as they act at large strain rate as supplementary crosslinks which can ease nucleation of crystallite, but still have enough mobility, when not stressed too rapidly, not to limit the growth of the crystallites. This complex effect is particularly evidenced during dynamic test performed under WAXS, at high strain rates (from $7.2 \mathrm{~s}^{-1}$, for $2 \mathrm{~Hz}$, to $1.44 \times 10^{2} \mathrm{~s}^{-1}$, for $2 \mathrm{~Hz}$ ) where it is found a much larger value of the maximum CI with $\mathrm{NR}_{0.8}$, especially at $2 \mathrm{~Hz}$. Such larger ability of this material to crystallize at large strain rate compared to more crosslinked rubber may have some practical advantage in rubber application as it is well known that SIC improves the material tearing properties.

\section{Appendix}

Thermoporosimetry is based on the fact that, when crystallized, solvent molecules constrained to small volumes form only relatively small crystallites and which therefore exhibit lower melting temperatures than the infinite crystal. Practically, NR samples are

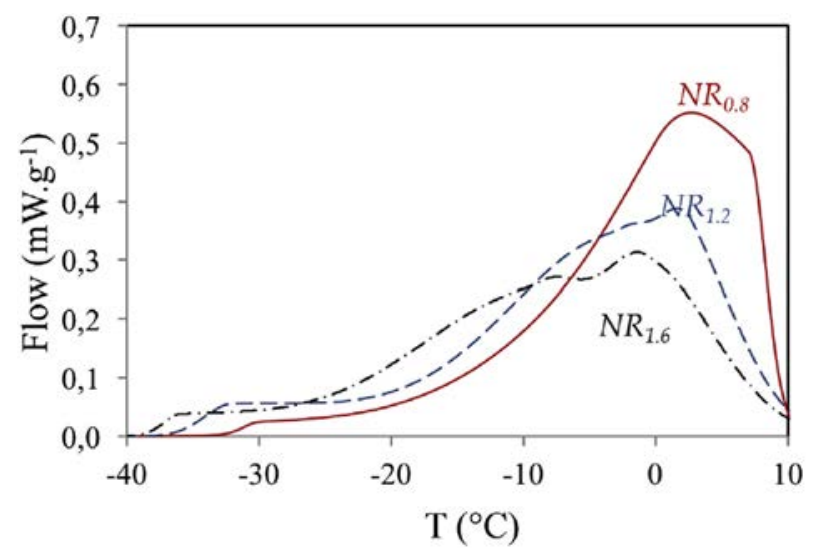

Fig. 10. Heating curves from thermoporosimetry experiment for $\mathrm{NR}_{0.8}$ (solid line), $\mathrm{NR}_{1.2}$ (dotted line) and $\mathrm{NR}_{1.6}$ (dash dotted line).

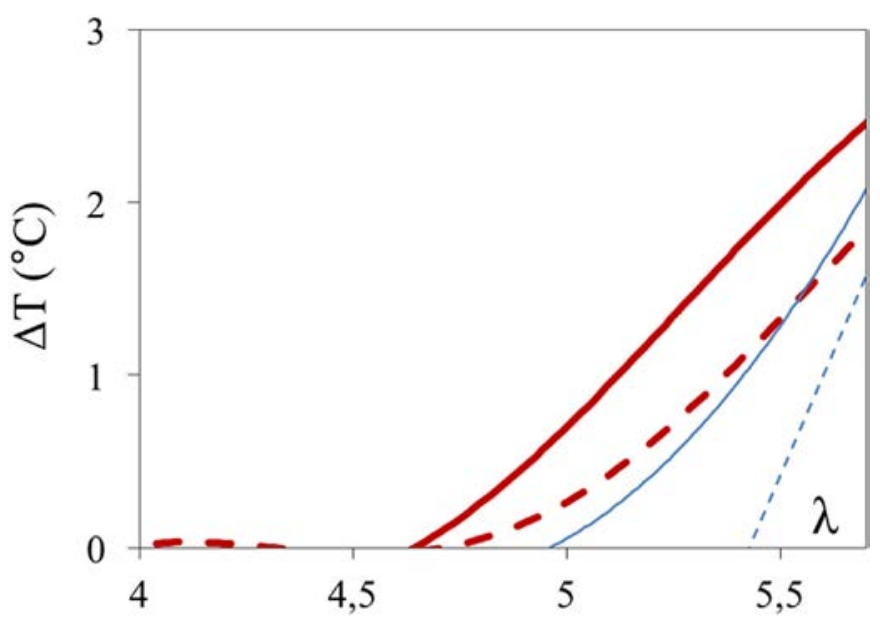

Fig. 11. Self-heating versus stretching ratio for $\mathrm{NR}_{0.8}$ (thick lines) and $\mathrm{NR}_{1.2}$ (thin lines) samples stretched at $5.6 \mathrm{~s}^{-1}$ (solid lines) and $2.8 \times 10^{1} \mathrm{~s}^{-1}$ (dotted lines).

put into a solvent (cyclohexane) during 3 days in order to reach the swelling equilibrium. They are then carefully extracted and put into an aluminium crucible. A Perkin Elmer Pyris diamond DSC is used. First, the sample is cooled down to $-50{ }^{\circ} \mathrm{C}$ at $10^{\circ} \mathrm{C} / \mathrm{min}$ followed by an isothermal step at $-50{ }^{\circ} \mathrm{C}$ during $2 \mathrm{~min}$. Finally, the sample is heated at $10{ }^{\circ} \mathrm{C} \mathrm{min}^{-1}$ up to $30^{\circ} \mathrm{C}$. When temperature increases, the first peaks that appear correspond to the melting of the cyclohexane entrapped in the network. The last peak (around $7{ }^{\circ} \mathrm{C}$ ) corresponds to the melting point of free cyclohexane (i.e. in excess). Melting peaks are deconvoluted by use of asymmetric Lorentzian functions. After removal of the peak of the free solvent, the signal is normalized by the swollen weight. The complete procedure can be found in reference 31 . Fig. 10 presents the comparative distribution of the solvent melting temperature for the three materials. The heating flow peak is shifted to the lowest melting temperatures when the average network chain density increases. This is expected by considering that the pore size is limited by the presence of nodes (indifferently chemical crosslinks or trapped entanglements). Moreover, the same figure shows that an increase of the average network chain density is associated to (i) a broader distribution of chain length between crosslinks and (ii) the creation of domains with a larger EAC density.

Fig. 11 presents the evolution of the thermal response of $\mathrm{NR}_{0.8}$ and $\mathrm{NR}_{1.2}$ samples stretched at room temperature and at two strain rates: $5.6 \mathrm{~s}^{-1}$ and $2.8 \times 10^{1} \mathrm{~s}^{-1}$. When strain rate increases, the stretching ratio at which heating appears is progressively increased; moreover, the maximum temperature variation reached at the maximum stretching ratio is decreased, suggesting a lower ability to crystallize. For a given strain rate, SIC onset is lower in $\mathrm{NR}_{0.8}$ samples than in $\mathrm{NR}_{1.2}$. Moreover, for a given strain rate and stretching ratio, heating is higher in $\mathrm{NR}_{0.8}$ samples whatever the strain rate. This suggests a higher ability of $\mathrm{NR}_{0.8}$ sample to crystallize.

\section{Acknowledgement}

The authors are indebted to the synchrotron SOLEIL and the local contact Dominique Thiaudière but also the synchrotron ESRF and the local contact Cyrille Rochas for providing the necessary beamline times and technical assistance in the experiments on the DiffAbs line and D2AM line respectively. 


\section{References}

[1] P. Rublon, B. Huneau, N. Saintier, S. Beurrot, A. Leygue, E. Verron, C. Mocuta, D. Thiaudiere, D. Berghezan, J. Synchrotron Radiat. 20 (2013) 105-109.

[2] S. Beurrot-Borgarino, B. Huneau, E. Verron, P. Rublon, Int. J. Fatigue 47 (2013) $1-7$.

[3] N. Saintier, G. Cailletaud, R. Piques, Mater. Sci. Eng. A-Struct. Mater. Prop. Microstruct. Process 528 (3) (2011) 1078-1086.

[4] J.B. Le Cam, E. Toussaint, Macromolecules 43 (10) (2010) 4708-4714.

[5] S. Trabelsi, P.A. Albouy, J. Rault, Macromolecules 35 (27) (2002) 10054-10061.

[6] S. Toki, I. Sics, B.S. Hsiao, M. Tosaka, S. Poompradub, Y. Ikeda, S. Kohjiya, Macromolecules 38 (16) (2005) 7064-7073.

[7] S. Trabelsi, P.A. Albouy, J. Rault, Macromolecules 36 (20) (2003) 7624-7639.

[8] Y. Miyamoto, H. Yamao, K. Sekimoto, Macromolecules 36 (17) (2003) 6462-6471.

[9] A.N. Gent, S. Kawahara, J. Zhao, Rubber Chem. Technol. 71 (4) (1998) 668-678.

[10] P.J. Flory, J. Chem. Phys. 15 (6) (1947) 397-408.

[11] W.R. Krigbaum, R.J. Roe, J. Polym. Sci. Part a-Gen. Pap. 2 (1964) 4391-4414.

[12] M. Yamamoto, J.L. White, J. Polym. Sci. Part a-2-Polym. Phys. 9 (8) (1971) 1399-1415.

[13] H. Dohi, S. Horiuchi, Polymer 48 (9) (2007) 2526-2530.

[14] S. Horiuchi, H. Dohi, Langmuir 22 (10) (2006) 4607-4613.

[15] S. Toki, T. Fujimaki, M. Okuyama, Polymer 41 (14) (2000) 5423-5429.

[16] J.M. Chenal, L. Chazeau, L. Guy, Y. Bomal, C. Gauthier, Polymer 48 (4) (2007) 1042-1046.

[17] M. Tosaka, S. Murakami, S. Poompradub, S. Kohjiya, Y. Ikeda, S. Toki, I. Sics, B.S. Hsiao, Macromolecules 37 (9) (2004) 3299-3309.

[18] J.F. Sanders, J.D. Ferry, R.H. Valentine, J. Polym. Sci. Part A-2 Polym. Phys. 6 (5) (1968) 967-980.

[19] M. Tosaka, S. Kohjiya, Y. Ikeda, S. Toki, B.S. Hsiao, Polym. J. 42 (6) (2010) 474-481.

[20] L. Gonzalez, J.L. Valentin, A. Fernandez-Torres, A. Rodriguez, A. Marcos-Fernandez, J. Appl. Polym. Sci. 98 (3) (2005) 1219-1223.

[21] M. Tosaka, K. Senoo, K. Sato, M. Noda, N. Ohta, Polymer 53 (3) (2012) 864-872.

[22] M. Tosaka, D. Kawakami, K. Senoo, S. Kohjiya, Y. Ikeda, S. Toki, B.S. Hsiao,
Macromolecules 39 (15) (2006) 5100-5105.

[23] R. Rauline, US. Patent, 5, 227, 425, (Michelin) (1993).

[24] P.J. Flory, J. Rehner, J. Chem. Phys. 11 (11) (1943) 521-526, 23.

[25] J.C. Mitchell, D.J. Meier, J. Polym. Sci. Part a-2-Polym. Phys. 6 (1968 $1689-1703$.

[26] J.R.S. Martinez, J.B. Le Cam, X. Balandraud, E. Toussaint, J. Caillard, Polymer 54 (11) (2013) 2727-2736.

[27] J.R.S. Martinez, J.B. Le Cam, X. Balandraud, E. Toussaint, J. Caillard, Polymer 54 (11) (2013) 2717-2726

[28] N. Candau, L. Chazeau, J.M. Chenal, C. Gauthier, R. Laghmach, T. Biben, E. Munch, Eur. Polym. J. 64 (2015) 244-252.

[29] G.R. Mitchell, Polymer 25 (11) (1984) 1562-1572.

[30] S. Trabelsi, Thesis, Orsay, France, (2002).

[31] N. Candau, R. Laghmach, L. Chazeau, J.-M. Chenal, C. Gauthier, T. Biben, E. Munch, Macromolecules 47 (16) (2014) 5815-5824.

[32] N. Candau, L. Chazeau, J.M. Chenal, C. Gauthier, J. Ferreira, E. Munch, C. Rochas, Polymer 53 (13) (2012) 2540-2543.

[33] N. Candau, L. Chazeau, J.M. Chenal, C. Gauthier, J. Ferreira, E. Munch, D. Thiaudière, Phys. Chem. Chem. Phys. 17 (23) (2015) 15331-15338.

[34] N. Candau, L. Chazeau, J.-M. Chenal, C. Gauthier, R. Laghmach, T. Biben, E. Munch, Polymer 60 (2015) 115-124.

[35] P.J. Phillips, N. Vatansever, Macromolecules 20 (9) (1987) 2138-2146.

36] E.N. Dalal, K.D. Taylor, P.J. Phillips, Polymer 24 (12) (1983) 1623-1630.

[37] J.D. Hoffman, G.T. Davis, J.I. Lauritzen Jr., Treatise on Solid State Chemistry, 1976. New York.

[38] A. Gros, M. Tosaka, B. Huneau, E. Verron, S. Poompradub, K. Senoo, Polymer 76 (2015) 230-236.

[39] N. Candau, L. Chazeau, J.M. Chenal, C. Gauthier, E. Munch, Phys. Chem. Chem. Phys. 18 (2016) 3472-3481.

[40] N. Candau, L. Chazeau, J.M. Chenal, C. Gauthier, E. Munch, Compos. Sci. Technol. 108 (2015) 9-15.

[41] K. Brüning, K. Schneider, S.V. Roth, G. Heinrich, Macromolecules 45 (19) (2012) 7914-7919.

[42] P.A. Albouy, G. Guillier, D. Petermann, A. Vieyres, O. Sanseau and P. Sotta. 53(15), 3313-3324 (2012). 